\title{
Discrimination and Mental Health Among Lesbian, Gay, and Bisexual Adults in the United States
}

\author{
Wendy B. Bostwick, \\ Northern Illinois University \\ Carol J. Boyd, \\ University of Michigan \\ Tonda L. Hughes, and \\ University of Illinois at Chicago \\ Brady West \\ Sean Esteban McCabe, University of Michigan
}

\begin{abstract}
Health disparities among sexual minority groups, particularly mental health disparities, are welldocumented. Numerous studies have demonstrated heightened prevalence of depressive and anxiety disorders among lesbian, gay, and bisexual groups as compared to heterosexuals. Some authors posit that these disparities are the result of the stress that prejudice and perceived discrimination can cause. The current study extends previous research by examining the associations between multiple types of discrimination, based on race/ethnicity, gender, and sexual orientation, and past year mental health disorders in a national sample of self-identified lesbian, gay and bisexual women and men $(n=577)$. Findings suggest that different types of discrimination may be differentially associated with past year mental health disorders. Notably, sexual orientation discrimination was associated with higher odds of a past year disorder only in combination with other types of discrimination. These findings point to the complexity of the relationship between discrimination experiences and mental health, and suggest that further work is needed to better explicate the interplay between multiple marginalized identities, discrimination and mental health.
\end{abstract}

\section{Keywords}

sexual minority groups; lesbian; gay; bisexual; sexual orientation discrimination; racial or ethnic discrimination; minority stress model

An ever-growing body of research points to numerous health disparities among lesbian, gay, bisexual and transgender populations, particularly in the realm of mental health (Bostwick et al. 2010; King et al. 2008; McCabe et al. 2009; Meyer, 2003). For example, a recent national study found that lesbian, gay and bisexual persons were one and a half to two times as likely

Correspondence concerning this article should be addressed to Wendy B. Bostwick, Northern Illinois University, Public Health and Health Education Programs, Wirtz Hall 255, Lincoln Highway, DeKalb, IL 60115 Electronic mail may be sent to 
as heterosexuals to report lifetime mood and anxiety disorders (Bostwick et al. 2010). Numerous authors have pointed to the institutional and interpersonal discrimination that sexual minorities face as a potential explanation for such disparities (Hatzenbuehler, et al., 2009; Mays \& Cochran, 2001; Meyer, 1995; 2003). One of the prevailing explanatory frameworks that explores this relationship is Meyer's minority stress model (Meyer, 2003; 1995).

An interdisciplinary model that synthesizes a large body of sociological and psychological work on stress and coping processes, Meyer's model (1995 (2003) suggests that health disparities among minority groups are best understood as arising from multiple contextual factors. That is, mental health differences are not determined solely by individual factors, such as personality, but are socially patterned and determined by circumstances in the environment and the complex interplay between individual factors and the socio-cultural context within which individuals reside. For those who occupy a marginalized minority status in the United States (e.g., non-White, non-male, non-heterosexual), this context too often includes institutional and interpersonal discrimination, prejudice and stigma.

In the minority stress model, "prejudice events" associated with a minority status, such as discrimination or expectations of prejudice, act as stressors in the lives of minority persons (Meyer 2003). These stressors are both unique and additive to everyday life stressors that all people experience. It is the excess stress associated with stigma and discrimination that contributes to the higher rates of mental health disorders often found in sexual minority population groups.

According to Krieger, discrimination is "a socially structured and sanctioned phenomenon, justified by ideology and expressed in interactions, among and between individuals and institutions, intended to maintain privileges for members of [certain] groups at the cost of deprivation of others" (Krieger 2000:41). Racism, sexism and homophobia are all manifestations and enactments of discrimination that have a number of deleterious effects. Numerous studies have established a relationship between experiences of discrimination and negative health outcomes, particularly mental health outcomes such as mood and anxiety disorders (e.g., Kessler, Mickleson and Williams 1999; Williams and Mohammad 2009; Yip, Gee, and Takeuchi 2008). For example, in a review of 138 studies of self-reported racism and health, Paradies (2006) noted that the most consistent relationship was between racism and poor mental health outcomes. Williams and Mohammed (2009) extended these findings in a review of studies published between 2005 and 2007. Of the 47 articles reviewed, nearly three-quarters $(\mathrm{n}=34)$ demonstrated a positive association between racial/ ethnic discrimination and poor mental health.

Most of the work in the area of discrimination and health has focused on racial discrimination; much less research is focused on gender-based or sexual-orientation discrimination. However, the studies that have explored these associations also find a relationship between discriminatory experiences and poor mental health. Two studies by Landrine, Klonoff and colleagues (Klonoff, Landrine and Campbell, 2000; Landrine et al. 1995) demonstrated a statistically significant relationship between women's experiences of sexism and poor mental health outcomes. Klonoff and colleagues (2000) found that although 
women exhibited higher mental health symptomology than men, when sexist events were accounted for, gender differences largely disappeared. The authors concluded that sexism plays a role in women's mental health and likely helps to explain mental health disparities between women and men.

Discrimination based on a minority sexual orientation or identity is similarly associated with poor mental health outcomes. Research has focused on psychological consequences of discrimination in the form of extreme events, such as hate crimes and other victimization (Herek, et al 1999), and on daily hassles in the form of heterosexist events (Swim, et al 2009). Both ends of this spectrum appear to negatively affect mental health among lesbian, gay and bisexual groups, resulting in depression and post-traumatic stress symptoms (Herek et al. 1999) or increased anxiety and anger (Swim et al. 2009).

In their 2001 study, Mays and Cochran (2001) used data from the National Survey of Midlife Development in the United States (MIDUS) to test the relationship between experiences of discrimination and mental health indicators among sexual minority adults compared to heterosexual adults. When the authors accounted for discriminatory experiences, the relationship between sexual identity and mental health outcomes was diminished, suggesting that mental health disparities across sexual orientation groups can be explained, in part, by experiences of discrimination (Mays and Cochran, 2001).

The above literature review demonstrates that single types of discrimination are associated with poorer mental health outcomes in a variety of population groups. However, given that most people's lived experiences are rooted in numerous intersecting identities, e.g., AfricanAmerican lesbian, bisexual Japanese-American man, the partitioning of discriminatory experiences likely provides a partial account of the effect(s) of discrimination on mental health.

Beyond the need to address multiple types of discrimination and variable effects on mental health outcomes, literature to date has rarely made a distinction between lesbian, gay or bisexual identities. There is evidence to suggest, however, that bisexual groups in particular have unique experiences with discrimination-including stigma and stereotyping - that are specific to their bisexual identity and that differ from the experiences of lesbian women and gay men (Balsam \& Mohr, 2007; Hequembourg \& Brailler, 2009). In addition to experiencing differential treatment by heterosexuals, bisexual persons also confront prejudicial behaviors and attitudes among lesbians and gays, or the "LGBT" community, of which bisexual groups — at least nominally—are a part (Bostwick, 2012; Bower, Gurevich \& Mathieson, 2002; Hequembourg \& Brailler, 2009). Bisexual groups are in the unfortunately unique position of confronting discrimination, and corresponding exclusion, from within their "own" community, which likely adds to the deleterious mental health consequences of discrimination.

To address these gaps in the literature, we examined perceived discrimination based on sexual orientation, race/ethnicity, and gender-alone and in combination-and their association(s) with past year mental health outcomes in a subsample of lesbian, gay and bisexual women and men from a large national probability sample. 


\section{Methods}

The current secondary analysis utilizes cross-sectional data from Wave 2 of the 2004-2005

National Epidemiologic Survey of Alcohol and Related Conditions (NESARC). NESARC's purpose is to estimate the prevalence of alcohol, drug and mental health disorders in the United States, among a non-institutionalized general population (Grant \& Kaplan, 2005). The NESARC is a longitudinal survey that began in 2001, with Wave 2 data collected in 2004-2005. Questions related to discrimination and sexual orientation were added in Wave 2.

The NESARC Wave 2 sample is representative of civilian adults, 20 years old and older, residing in non-institutionalized settings in the United States. Data were collected in face-toface interviews conducted in respondents' homes. The response rate at baseline was $81.0 \%$ (for a more detailed discussion of methods see Ruan et al. 2008). A total of 34,653 interviews were conducted among the eligible respondents. The Wave 2 response rate was $86.7 \%$ and the cumulative response rate for both Waves 1 and 2 was $70.2 \%$.

NESARC data are weighted based on a number of factors, including oversampling of Blacks, Hispanics and those aged 18-24 at baseline, and adjustments for differential nonresponse across groups. Weights for sample respondents were also adjusted to conform to national 2000 Census estimates of the population based on region, age, sex, race and ethnicity (Ruan et al. 2008). The NESARC design was reviewed and approved by the United States Census Bureau and the Office of Budget and Management. The current study received Institutional Review Board approval from the principal investigator's institution.

\section{Measures}

Past year discrimination was measured using questions derived from the Experiences of Discrimination scales developed by Krieger and colleagues (Krieger et al 2005; Krieger \& Sidney 1997; Ruan et al. 2008). Each type of discrimination was assessed with six questions that asked respondents how often they "[had] experienced discrimination, been prevented from doing something, or been hassled or made to feel inferior in any of the following situations" due to race, Hispanic or Latino ethnicity, being male or female, or because they were assumed to be gay, lesbian or bisexual. For the purpose of this these analyses, race and ethnicity questions were combined into a single "racial/ethnic discrimination" variable. Further, though the original question asked about discrimination based on sex, i.e., being female or male, for clarity's sake and ease of presentation, we have chosen to label this variable "gender" discrimination.

Discrimination questions covered domains such as health care, the public sphere, and employment and training. Two of the six questions inquired about verbal and physical assault or harm. Questions for each type of discrimination were parallel, with the exception of the gender discrimination measure, which excluded the question about physical assault or threats of harm, and asked about employment separately.

Response options were never (0), almost never (1), sometimes (2), fairly often (3) and very often (4). Given that Likert-type response scales were used, rather than count response 
scales, we dichotomized responses (any/none) and created an indicator of any discrimination for each of the three types of discrimination by summing responses to the six questions. In addition, similar to previous work (Krieger and Sidney 1997; McCabe et al. 2010), we created mutually exclusive discrimination variables that indicated whether respondents reported experiencing racial/ethnic, sexual orientation, or gender discrimination alone and independent of other types (e.g., sexual orientation discrimination only), or in combination (e.g., sexual orientation and gender discrimination in the past year), including experiencing all three types of discrimination in the last year.

To explore the unique effects of individual discrimination types in the logistic regression model, respondents who reported only sexual orientation discrimination and no other type (i.e., gender or race based discrimination) constituted one category, those who reported only gender discrimination and no other type constituted another category, and so on, such that there was no overlap between groups and their discrimination experiences.

In addition to the discrete discrimination categories, we also created three groups to allow for the exploration of additive effects: single discrimination type, dual discrimination, and triple discrimination. The "single" category included only respondents who reported a single type of discrimination. The "dual" category included those who reported experiencing two types of discrimination to the exclusion of a third, and the final category included those respondents who reported experiencing sexual orientation, gender and race/ethnic discrimination in the past year.

Finally, for each of the three types of discrimination, we computed a total sum score of the six Likert-type items measuring the frequency of each type of discrimination (with minimum value 0 and maximum value 24 for each type of discrimination). Since responses were not strict counts, but rather, relied on more qualitative assessments of frequency (e.g., almost never or fairly often) these summed scores represent respondents' subjective assessment of more frequent experiences of each discrimination event. Higher scores on these three variables, therefore, indicate reporting more frequent experiences of a particular type of discrimination.

Past year mental health disorders were assessed using the Alcohol Use Disorder and Associated Disabilities DSM-IV Interview Schedule (AUDADIS-IV). The AUDADIS-IV assesses mood disorders (major depression, dysthymia, mania and hypomania) and anxiety disorders (panic disorder with and without agoraphobia, social phobia, specific phobia and generalized anxiety disorder). Consistent with DSM-IV criteria, mood and anxiety disorders associated with a medical condition or with bereavement are ruled out in the diagnostic algorithm and are not included in the calculation of prevalence estimates of these disorders (Hasin et al, 2005). All mood and anxiety disorders were combined to create a single dichotomous (any/none) indicator of past year mental health disorders.

Sexual identity was assessed by showing respondents a preprinted card with response options and asking "Which of the categories on the card best describes you?" (1) heterosexual (straight), (2) gay or lesbian, (3) bisexual, or (4) not sure?" Those who answered "not sure" were omitted from these analyses. 
Demographic and control variables included in the current analyses were sex, age, (18-24, 25-44, 45-64, 65 and above) race (white, black, Native American, Asian, Hispanic) and income (less than $\$ 19,999, \$ 20,000-\$ 34,999, \$ 35,000-\$ 69,999, \$ 70,000$ or higher).

Because only respondents who identified as lesbian, gay or bisexual were asked about sexual orientation discrimination, we restricted the analytic sample to this group $(\mathrm{n}=577)$, and used methods appropriate for analyses of subpopulations based on survey data (e.g., West et al. 2008).

\section{Data Analysis}

A complex, multi-stage sample design featuring stratification and clustering of the target NESARC population was used to select the sample. Sampling weights for Wave 2 respondents were computed by NESARC staff to ensure that the weighted sample continued to represent the noninstitutionalized U.S. population, even after Wave 1 attrition. All analytic techniques in this study were design-based, using the sampling weights to calculate estimates of population parameters and specialized variance estimation techniques (i.e., Taylor Series Linearization) to accommodate the complex design features of the NESARC sample. All analyses were performed using the SUDAAN statistical software package (Version 10.0.1).

Analyses began with the estimation of key descriptive parameters for the sexual minority subsample (e.g., the percentage experiencing sexual orientation discrimination or any mental health disorders in the past year). We then used design-based regression modeling procedures (Heeringa, West, and Berglund 2010) to examine relationships between the dependent variable indicating any past-year mental health disorder and the independent variables measuring discrimination experiences, sexual identity, race, sex, age, and income. Specifically, we fit two models, considering discrimination experiences based on sexual orientation, race, and gender (and their various combinations) to determine whether different forms of discrimination experiences were associated with varying risk of mental health disorders when adjusting for sexual identity, race, sex, age, and income.

\section{RESULTS}

Estimates of demographic distributions for the entire NESARC Wave 2 sample $(n=34,652)$, and stratified by gender, are provided in Tables $1 \mathrm{a} \& 1 \mathrm{~b}$ to demonstrate differences among lesbian/gay, bisexual and heterosexual groups. An estimated $2 \%$ of the sample identified as lesbian, gay or bisexual. Nearly twice as many men identified as gay compared to bisexual ( $n=190$ and $n=81$, respectively). Compared to bisexual and heterosexual men, gay men were significantly younger $(\chi 2=52.6, \mathrm{p}<.01)$ and more likely to report any past year mental health disorders $(\chi 2=12.6, \mathrm{p}<.01)$. Among women, there were significant differences across groups based on age, income, and any past year mental health disorder. Bisexual women were younger, poorer and much more likely to report any past year disorder, as compared to lesbian and heterosexual women.

Tables $2 \mathrm{a} \& 2 \mathrm{~b}$ provide prevalence estimates for past-year discrimination based on sexual orientation and race/ethnicity among the sexual minority subsample only, stratified by 
gender. Among sexual minority men (Table 2a), gay men were significantly more likely than bisexual men to report any sexual orientation discrimination in the past year: 50.0\% versus $24.2 \%(\chi 2=11.3, p<.01)$. More specifically, gay men were more likely to report discrimination related to treatment in a healthcare setting, discrimination in public (on the street, in stores, or restaurants), being called names, and being made fun of, including being threatened with harm.

Racial discrimination was more common among sexual minority men of color, with nearly $60 \%$ reporting any discrimination in the past year, as compared to $23.8 \%$ of White sexual minority men $(\chi 2=14.7, \mathrm{p}<.001)$ - with the largest differences related to public acts and being called names.

Table $2 \mathrm{~b}$ provides results for sexual minority women. Similar to men, lesbian women were more likely than bisexual women to report any past year discrimination, and sexual minority women of color were more likely than White sexual minority women to report any past year discrimination. Of the six specific discrimination experiences, lesbians differed significantly from bisexual women on five of the sexual orientation-based experiences. In terms of racial discrimination, sexual minority women of color were significantly more likely than their White counterparts to report experiences related to discrimination in public (34.1\% vs $12.7 \%, \chi 2=10.5, \mathrm{p}<.001)$ and to getting admitted to school or a training program, and in the courts or obtaining housing $(22.0 \%$ vs $2.9 \%, \chi 2=12.6, \mathrm{p}<.001)$.

We also examined the estimated prevalence of discrimination types alone and in combination, stratified by gender (Tables $3 \mathrm{a} \& 3 \mathrm{~b}$ ). Again, bisexual men were less likely than gay men to report any discrimination experiences and sexual minority men of color were more likely than White counterparts to report discrimination of any type in the past year. In particular, sexual minority men of color were much more likely to report experiencing all three types of discrimination (sexual orientation, race, gender) in the past year (24.7\% compared to $6.6 \%$ among White men). In contrast, we found no significant racial/ethnic differences among women. Although bisexual women were less likely overall to report any discrimination as compared to lesbians, differences emerged between the two groups based on the combination of discrimination types. For example, lesbians reported a higher frequency of sexual orientation discrimination alone, as well as sexual orientation and gender discrimination in combination, whereas bisexual women reported a higher frequency of gender discrimination alone, and gender and race discrimination in combination.

Table 4 presents results from multivariate logistic regression analyses for single, dual, or triple discrimination and any past year mental health disorder. No single type of discrimination predicted past year mental health disorder, but both dual and triple discrimination were significantly associated with higher odds of any past year mental health disorder, as compared to those who reported no past year discrimination.

Results from multivariate logistic regression analyses are presented in Table 5, wherein each combination of discrimination type is considered as a predictor of any past-year mental health disorder. After controlling for sexual identity, race, sex and income, only certain types of discrimination were significantly associated with mental health disorder. The odds 
of any past year mental health disorder among those who reported past year gender discrimination alone were estimated to be more than two times as high ( $\mathrm{AOR}=2.28,95 \%$ $\mathrm{CI}=1.09,4.78$ ) as respondents who reported no past year discrimination. Odds were also significantly higher for those who reported sexual orientation and racial/ethnic discrimination combined $(\mathrm{AOR}=2.25,95 \% \mathrm{CI}=1.02,4.95)$ and gender and $\mathrm{racial} / \mathrm{ethnic}$ discrimination combined $(\mathrm{AOR}=4.30,95 \% \mathrm{CI}=1.91,9.68)$. The odds of any mental health disorder in the past year for respondents who reported all three types of discrimination were estimated to be more than three times higher than those reporting no discrimination $(\mathrm{AOR}=3.31,95 \% \mathrm{CI}=1.45,6.74)$.

Finally, we fit a logistic regression model predicting the probability of any past year mental health disorder as a function of the three total summed scores for each type of discrimination (data not shown). The model controlled for sexual identity, age, race/ethnicity, sex, and income. This model was fitted to examine the independent effects of the frequency of each type of discrimination on the overall probability of having any past-year mental health disorder. The only significant predictor among the three different measures of total discrimination experiences was the total summed score for gender-related discrimination $(\mathrm{AOR}=1.15,95 \% \mathrm{CI}=1.01-1.31)$. This finding suggests that every one-unit increase in the total gender discrimination score (based on the six items measuring different types of gender discrimination) increases the odds of a past-year mental health disorder by about $15 \%$, holding the total experience scores for racial and sexual orientation discrimination and the other socio-demographic predictors fixed.

\section{DISCUSSION}

This study is one of the first to examine the relationship between multiple types of discrimination and mental health disorders in a large national probability sample of lesbian, gay and bisexual respondents. Experiences of discrimination were common, with nearly two-thirds of the sample reporting at least one experience of sexual orientation, racial/ethnic or gender discrimination in the past year. A greater number of types of discrimination were generally associated with a higher probability of reporting a past year mental health disorder. Results, however, were mixed in regard to which combinations of discrimination type predicted mental health disorders. For example, although sexual orientation discrimination alone was not associated with higher odds of a mental health disorder, respondents who reported both sexual orientation and racial/ethnic discrimination or sexual orientation, racial/ethnic and gender discrimination were significantly more likely to meet criteria for a mental health disorder. Further, racial discrimination alone was not associated with mental health disorders, but the combination of this with gender discrimination or sexual orientation discrimination was significantly associated with increased odds of past year mental health disorder. Gender discrimination was the only single type of discrimination associated with an increased odds of past year disorder.

In addition, when discrimination "scales" were created for each specific discrimination type, the gender discrimination scale was the only one that was significantly associated with a past year mental health disorder. This further supports the notion that the relationship between discrimination and mental health is influenced by more than simply quantity, i.e., 
those reporting more frequent discrimination experiences will necessarily report poorer mental health, and that qualitative distinctions, such as type of discrimination, are relevant.

The finding that different constellations of discriminatory experiences were associated with poor mental health outcomes in some instances, but not others, can be explained, in part, by psychological and sociological aspects of the minority stress model. Meyer suggests that characteristics of identity, such as valence (a person's subjective evaluation of their identity as positive, negative or neutral) and prominence (where a particular identity is situated within an individual's identity hierarchy), influence the relationship between minority status, related stressors, (e.g., perceived discrimination) and subsequent health outcomes. For example, discrimination based on a prominent identity may result in more negative mental health consequences than discrimination based on an identity that is less salient to the individual.

There are also group-level processes and resources to consider. Social support may serve to buffer the negative effects of identity-based stressors, such as sexual orientation or racial/ ethnic discrimination (Meyer, 2003; Miller \& Major, 2000). Depending upon the type(s) and/or combination(s) of identity-based discrimination experienced, coping resources and social support may vary, and, in turn, differentially moderate the effect of such experiences on mental health and well-being. For example, although racial/ethnic minority groups typically have access to others like themselves from birth, this is generally not the case for lesbian, gay and bisexual groups (Ueno, 2005). And although sexual minority groups of color may have access to social support and supportive networks vis-à-vis their racial/ethnic identity experiences, this may not be the case for sexual orientation discrimination (Bowleg et al, 2003; Greene, 1994; Moore, 2010) or discrimination experiences related to the intersection of these identities (Meyer, 2010). The interplay of these social-psychological factors may account for different types (and combinations) of discrimination affecting mental health in different ways.

The supposition, however, that these variables explain the current findings is highly provisional, as the original NESARC survey instrument did not assess social support or other social-psychological factors.

Another finding that warrants further research concerns the bisexual group. As shown in the current and other studies (Bostwick et al. 2010; King et al. 2008; Jorm et al. 2002), when compared with heterosexuals and lesbians/gay men, bisexuals often report some of the worst mental health outcomes. Within the context of the minority stress model, one might expect those with the worst mental health outcomes-i.e., bisexual groups-to correspondingly report the highest prevalence of discrimination. However, in the current study, the bisexual group was significantly less likely than lesbian and gay counterparts to report any discriminatory experiences. These results are consistent with recent work by Herek (2009) who attributed the higher rates of discrimination among lesbian women and gay men to their greater visibility (i.e., "outness") in the workplace and other settings that may make them more vulnerable to discrimination (Herek, 2009). 
Such findings do not necessarily call the basic premise of the minority stress model into question, but rather, bring to the forefront components of the model that have heretofore generally gone untested (excepting Meyer, 1995). Overt discrimination is only one component of the minority stress processes specified in Meyers's model (2003); also included are expectations of rejection and internalization of negative attitudes. These factors may be more salient to understanding the stark mental health disparities among bisexual populations.

There is amassing evidence that experiences of stigma, prejudice and discrimination are at least qualitatively different for bisexuals, as compared to lesbians and gay men, such that expectations of rejection would likely vary as a result. Perhaps most notable is that bisexual persons are often rejected by and excluded from a community they are supposedly a part of (Bostwick, 2012; Hequembourg \& Brailler, 2009; Ross, et. al., 2010). Recent work confirms that bisexual persons see themselves as less connected to the LGBT community. For example, among a national probably sample, Herek and colleagues found that bisexuals were less likely than gays and lesbians to identify with a sexual-minority community, or to see community membership as a reflection of themselves (Herek, Norton, Allen \& Sims, 2010). Work by Kertzner and colleagues also demonstrates a lack of connectedness to the LGBT community and poor social well-being among bisexuals as compared to lesbian and gay persons (Kertnzer, Meyer, Frost \& Stirratt, 2009). However, they found that the association between social well-being and bisexuality was fully mediated by community connectedness and identity valence.

A further distinction between the experiences of bisexuals and those of lesbians and gays is the devaluation of the bisexual identity itself. The social and cultural (and too often scientific) treatment of bisexuality as an identity that is inauthentic or not "real" (Carey, 2005) fosters a larger context in which bisexual persons are constantly having to defend and affirm the legitimacy of who they are (Gurevich, et. at., 2007). The stress associated with this identity contestation and the implicit demands for proof are almost certainly interwoven with the minority stress processes that Meyer delineates in his model. Meyer acknowledges that his model "fails to distinguish bisexual individuals from lesbian and gay individuals" (2003: 690). Findings from the current study suggest a need for research that explicitly explores the unique stressors faced by bisexual persons.

The consideration of psycho-social variables is important to the larger project of understanding mental health disparities (Aneshensel, 2009) and to the patterning of health inequities more broadly (Krieger, 2001); the current findings point to the need for further attention to and exploration of such variables among sexual minority populations. However, an over-emphasis on these variables may inadvertently obscure equally important socially determined and structural contributions to heightened odds of mental health disorders. Racebased and gender-based discrimination, in particular, occur over the lifecourse. Although this may, on the one hand, build coping repertoires, there are consequences far beyond intraand inter-personal levels. Institutionalized racism and sexism — and their legacysignificantly affect a number of highly salient factors vis-à-vis health, including economic, social and educational opportunities, as well as health care access and treatment (Krieger, 2000). A deeper analysis of this is beyond the scope of the present paper. However, current 
findings support the need for multi-level theories and frameworks that incorporate not just multiple, intersecting identities and their interplay, but the multiple and intersecting levels of influence that explain the relationship between discrimination and health outcomes (see Krieger, 2001 for an example of such a perspective).

Taken collectively, results provide empirical support for the contention that experiences of discrimination may help to explain mental health disparities among lesbian, gay and bisexual populations. Findings also suggest that to the extent that discrimination based on sexual orientation is associated with poor mental health outcomes among sexual minority groups, it most likely operates in conjunction with other forms of discrimination. Such an understanding is consistent with more recent "intersectional" approaches to sexual minority groups' experiences related to identity/ies (Bowleg 2008; Narvaez et al. 2009). This approach posits that people and their experiences are irreducible to singular parts or identities, and that social categories such as "woman", "bisexual", and "African-American" are co-determining and interdependent. That is, such identities and the life experiences associated with them—including discrimination—are not necessarily discrete or separable from one another.

The current study attempted a more interdependent or intersectional approach to identity by examining the relationship between discrimination experiences and mental health separately for men and women of color based on their sexual identity. By testing interaction effects, including a three-way interaction between gender, race and sexual orientation, we considered that discrimination may be experienced differently, and putative associations with mental health outcomes may differ for those who occupy several minority statuses (data not shown). Preliminary data suggested the possibility of different patterns among the groups, but small cell sizes led to unstable odds ratio estimates and very large confidence intervals. Studies with larger samples of both racial/ethnic and sexual minority groups are needed to more fully assess the potential associations between multiple types of discrimination and mental health across multiple co-occurring identities.

These findings are somewhat different from other work that has compared multiple types of discrimination and their association with health outcomes. Specifically, McCabe and colleagues (2010) considered past year and lifetime sexual orientation, gender and racial/ ethnic discrimination and their associations with past year substance use disorders. Whereas the current paper found a number of associations between discrimination and mental health disorders, the McCabe paper demonstrated a consistent pattern of non-association. Only the combination of past year sexual orientation and gender and racial discrimination was associated with a substance use disorder. Given the incomparability of the findings, it could be that the mechanisms underlying the relationship between discrimination and substance use disorders differs from those underlying the relationship between discrimination and depressive and anxiety disorders.

Findings must be considered in light of some limitations. Wave 2 of the NESARC asked only sexual minority respondents about sexual orientation discrimination, whereas all groups were asked about race and gender discrimination. Consequently, we focused solely on lesbian, gay and bisexual groups, who represented a relatively small subsample of the larger 
sample. Insufficient power may have contributed to some of the non-significant findings. Beyond statistical concerns, the absence of heterosexuals in the study sample also limits theoretical contributions. The inclusion of a heterosexual group would allow researchers to more fully address the various ways in which constellations of discrimination affect people, and provide a better basis for making useful claims regarding multiple and co-occurring identities and how these shape life experiences.

Though the NESARC is a longitudinal study, only Wave 2 of the survey included questions about sexual orientation or discrimination. Thus, the data used in analyses are crosssectional, precluding the ability to establish causal order. It is possible that respondents who experienced a mood or anxiety disorder in the past year were more likely to perceive experiences as discriminatory. However, previous longitudinal studies point to discrimination preceding mental health problems, with increases in discrimination corresponding to increases in mental health issues (Brown et al., 2000, Brody et al., 2006; Schulz et al., 2006). Longitudinal work focusing on sexual orientation and/or multiple forms of discrimination will help to further elucidate the mechanisms that link the two.

In addition, the past-year time frame of the discrimination measure may not capture events that occurred in the more distant past, i.e., greater than 12 months ago, yet such events may still impact past-year mental health. Similarly, the mental health sequelae of a recent discriminatory experience may not have yet had time to emerge. In both instances, the association between discrimination and mental health may be attenuated. Again, longitudinal studies can help to address such concerns.

The use of a validated measure of discrimination is a strength of the current investigation. However, the measure did not assess the frequency or intensity of discrimination experiences, nor the level of stress associated with such experiences. As Landrine and colleagues(2006) note, the absence of questions related to appraisal or meaning ascribed to discriminatory experiences by the targets misses an important opportunity to assess such events within a stress and coping framework. It should be noted that updated versions of the Experiences of Discrimination [EOD] scale include an assessment of the frequency of experiences.) Further, the discrimination measure primarily focused on individual-level, event-based experiences. The deleterious effects of institutionalized discrimination, such as many state's anti-gay marriage laws, may be equally or more damaging to the mental health status of LGB groups (Hatzenbuehler et. al., 2009).

The study has a number of strengths that should also be considered. It uses data from the NESARC, which includes the largest national probability sample of LGB-identified adults to date. In addition, the NESARC uses validated measures to assess experiences of discrimination as well as DSM-IV mental health disorders. Hence, these findings are likely generalizable to many lesbian, gay and bisexual persons.

In conclusion, this investigation provides support for the central hypothesis of the minority stress model which posits that prejudicial and discriminatory experiences may contribute to increased mental health disorders among minorities. It extends previous work by incorporating multiple types of discrimination. The finding that past year sexual orientation 
discrimination alone did not predict past year mental health disorders suggests that further work is needed to more fully explicate the interplay between multiple marginalized identities, discrimination and mental health.

\section{Acknowledgments}

The development of this article was supported by research grants DA023055 and DA007267 from the National Institute on Drug Abuse and National Institute on Alcohol Abuse and Alcoholism, National Institutes of Health. Neither had any role in study design, the collection, analysis, and interpretation of data, the writing of the report, or the decision to submit the article for publication.

The first author wishes to thank Christina Papadimitriou and Christina Brennan for their assistance in the preparation of this article.

\section{References}

Aneshensel C. Toward explaining mental health disparities. Journal of Health and Social Behavior. 2009; 50:377-394. [PubMed: 20099446]

Balsam KF, Mohr JJ. Adaptation to sexual orientation stigma: A comparison of bisexual and lesbian/gay adults. Journal of Counseling Psychology. 2007; 54(3):306.

Bostwick W. Assessing Bisexual Stigma and Mental Health Status: A Brief Report. Journal of Bisexuality. 2012; 12(2):214-222. [PubMed: 24683314]

Bostwick WB, Boyd CJ, Hughes TL, McCabe SE. Sexual orientation and the prevalence of mood and anxiety disorders in the United States. American Journal of Public Health. 2010; 100:468-475. [PubMed: 19696380]

Bowleg L. When black + lesbian + woman does not = black lesbian woman: The methodoligical challenges of qualitative and quantitative intersectionality research. Sex Roles. 2008; 59:312-325.

Bowleg L, Juang J, Brooks K, Black A, Burkholder G. Triple jeopardy and beyond: Multiple minority stress and resilience among black lesbians. Journal of Lesbian Studies. 2003; 7:87-108. [PubMed: 24831386]

Bower J, Gurevich M, Mathieson C. (Con) tested identities: Bisexual women reorient sexuality. Journal of Bisexuality; Journal of Bisexuality. 2002

Brody G, Chen YF, Murry V, Ge X, Simmons R, Gibbons F, et al. Perceived discrimination and the adjustment of African American youths: A five-year longitudinal analysis with contextual moderation effects. Child Development. 2006; 77:117-131.

Brown T, Williams D, Jackson J, Neighbors H, Torres M, Sellers S, et al. Being black and feeling blue: The mental health consequences of racial discrimination. Race and Society. 2000; 2:117-131.

Carey, B. Bisexuality revisited. The New York Times; 2005. Straight, gay, or lying?; p. F1

Cohen, J.; Cohen, P.; West, S.; Aiken, L. Applied Multiple Regression/Correlation Analysis for the Behavioral Sciences. New York: Routledge Academic Press; 2002.

Grant, B.; Kaplan, K. Source and accuracy statement for the Wave 2 National Epidemiolgic Survey on Alcohol and Related Conditions (NESARC). Rockville, Maryland: National Institute on Alcohol Abuse and Alcoholism; 2005.

Greene B. Ethnic minority lesbians and gay men: Mental health and treatment issues. Journal of Consulting \& Clinical Psychology. 1994; 62:243-251. [PubMed: 8201060]

Gurevich, M.; Bower, J.; Mathieson, C.; Dhayanandhan, B. What do they look like and are they among us? Bisexuality, (Dis)closure and (Un)viability. In: Clark, V.; Peel, E., editors. Out in Psychology: Lesbian, Gay, Bisexual, Trans and Queer Perspectives. 2007. p. 217-241.

Hasin D, Goodwin R, Stinson F, Grant B. Epidemiology of major depressive disorder: Results from the National Epidemiologic Survey on Alcoholism and Related Conditions. Archives of General Psychiatry. 2005; 62:1097-1106. [PubMed: 16203955]

Hatzenbuehler M, Keyes K, Hasin D. State-level policies and psychiatric morbidity in lesbian, gay and bisexual populations. American Journal of Public Health. 2009; 99:2275-2281. [PubMed: 19833997] 
Heeringa, S.; West, B.; Berglund, P. Applied survey data analysis. Boca Raton: Taylor \& Francis; 2010.

Herek GM. Hate Crimes and Stigma-Related Experiences Among Sexual Minority Adults in the United States Prevalence Estimates From a National Probability Sample. Journal of Interpersonal Violence. 2009; 24(1):54-74. [PubMed: 18391058]

Herek G, Gillis R, Cogan J. Psychological sequelae of hate-crime victimization among lesbian, gay and bisexual adults. Journal of Consulting and Clinical Psychology. 1999; 67:945-951. [PubMed: 10596515]

Herek GM, Norton AT, Allen TJ, Sims CL. Demographic, psychological, and social characteristics of self-identified lesbian, gay, and bisexual adults in a US probability sample. Sexuality Research and Social Policy. 2010; 7(3):176-200. [PubMed: 20835383]

Hequembourg AL, Brallier SA. An exploration of sexual minority stress across the lines of gender and sexual identity. Journal of homosexuality. 2009; 56(3):273-298. [PubMed: 19319738]

Jorm A, Korten A, Rodgers B, Jacomb P, Christensen H. Sexual orientation and mental health: Results from a community survey of young and middle-aged adults. The British Journal of Psychiatry. 2002; 180:423-527. [PubMed: 11983639]

Kertzner RM, Meyer IH, Frost DM, Stirratt MJ. Social and Psychological Well-Being in Lesbians, Gay Men, and Bisexuals: The Effects of Race, Gender, Age, and Sexual Identity. American Journal of Orthopsychiatry. 2009; 79(4):500-510. [PubMed: 20099941]

Kessler R, Mickelson K, Williams D. The prevalence, distribution, and mental health correlates of perceived discrimination in the United States. Journal of Health and Social Behavior. 1999; 40:208-230. [PubMed: 10513145]

King M, Semlyen J, Tai S, Killaspy H, Osborn D, Popelyuk D, et al. A systematic review of mental disorder, suicide, and deliberate self-harm in lesbian, gay and bisexual people. BMC Psychiatry. 2008; 8

Klonoff E, Landrine H, Campbell R. Sexist discrimination may account for well-known gender differences in pscyhiatric symptoms. Psychology of Women Quarterly. 2000; 24:93-99.

Krieger, N. Discrimination and health. In: Berkman, L.; Kawachi, I., editors. Social Epidemiology. New York: Oxford University Press; 2000. p. 36-75.

Krieger N. Theories for social epidemiology in the 21st Century: An Ecosocial perspective. International Journal of Epidemiology. 2001; 30:668-677. [PubMed: 11511581]

Krieger N, Sidney S. Prevalence and health implications of anti-gay discrimination: A study of black and white women and men in the CARDIA cohort. International Journal of Health Services. 1997; 27:157-176. [PubMed: 9031018]

Krieger N, Smith K, Naishadham D, Hartman C, Barbeau E. Experiences of discrimination: Validity and reliability of a self-report measure for population health research on racism and health. Social Science \& Medicine. 2005; 61:1576-1596. [PubMed: 16005789]

Landrine H, Klonoff E, Corral I, Fernandez S, Roesch S. Conceptualizing and measuring ethnic discrimination in health research. Journal of Behavioral Medicine. 2006; 29:79-94. [PubMed: 16470345]

Mays V, Cochran S. Mental health correlates of perceived discrimination among lesbian, gay, and bisexual adults in the United States. American Journal of Public Health. 2001; 91:1869-1876. [PubMed: 11684618]

McCabe S, Bostwick W, Hughes T, West B, Boyd C. The relationship between discrimination and substance use disorders among lesbian, gay, and bisexual adults in the United States. American Journal of Public Health. 2010; 100:1946-1952. [PubMed: 20075317]

McCabe S, Hughes T, Bostwick W, West B, Boyd C. Sexual orientation, substance use behaviors and substance use disorders among lesbian, gay and bisexual adults in the United States. Addiction. 2009; 104:1333-1345. [PubMed: 19438839]

McCoy S, Major B. Group identification moderates emotional responses to perceived prejudice. Personality and Social Psychology Bulletin. 2003; 29:1005-1017. [PubMed: 15189619]

Meyer D. Evaluating the severity of hate-motivated violence: Intersectional differences among LGBT hate crime victims. Sociology. 2010; 44:908-995. 
Meyer I. Minority stress and mental health in gay men. Journal of Health and Social Behavior. 1995; 36:38-56. [PubMed: 7738327]

Meyer I. Prejudice, social stress, and mental health in lesbian, gay, and bisexual populations: Conceptual issues and research evidence. Psychological Bulletin. 2003; 129:674-697. [PubMed: 12956539]

Meyer I. The right comparisons in testing the minority stress hypothesis: Comment on Savin-Williams, Cohen, Joyner and Rieger. Archives of Sexual Behavior. 2010; 39:1217-1219. [PubMed: 20809370]

Meyer I, Schwartz S, Frost D. Social patterning of stress and coping: Does disadvantaged social statuses confer more stress and fewer coping resources. Social Science \& Medicine. 2008; 67:368379. [PubMed: 18433961]

Miller, C.; Major, B. Coping with Stigma and Prejudice. In: Heatherton, T.; Kleck, R.; Hebl, M.; Hull, J., editors. The Social Psychology of Stigma. New York: Guilford Press; 2000.

Moore M. Articulating a politics of (multiple) identities: Sexuality and inclusion in black community life. DuBois Review: Social Science Research on Race. 2010; 2:1-20.

Narvaez R, Meyer I, Kertzner R. A qualitative approach to the intersection of sexual, ethnic, and gender identities. Identity: An International Journal of Theory and Research. 2009; 9:63-89.

Paradies Y. A systematic review of empirical research on self-reported racism and health. International Journal of Epidemiology. 2006; 35:888-901. [PubMed: 16585055]

Poteat P, Aragon S, Espelage D, Koenig B. Psychosocial concerns of sexual minority youth: Complexity and caution in group differences. Journal of Consulting and Clinical Psychology. 2009; 77:196-201. [PubMed: 19170465]

Ross L, Dobinson C, Eady A. Perceived determinants of mental health for bisexual people: A qualitative examination. American Journal of Public Health. 2010; 100:496-502. [PubMed: 20075326]

Ruan J, Goldstein R, Chou P, Smith S, Saha T, Pickering R, et al. The alcohol use disorder and associated disabilities interview schedule-IV (AUDADIS-IV): Reliability of new psychiatric diagnostic modules and risk factors in a general population sample. Drug and Alcohol Dependence. 2008; 92:27-36. [PubMed: 17706375]

Rust, P. Bisexuality and the challenge to lesbian politics. New York: New York University Press; 1995.

Saewyc E, Homma Y, Skay C, Bearinger L, Resnick M, Reis E. Protective factors in the lives of bisexual adolescents in North America. American Journal of Public Health. 2009; 99:110-117. [PubMed: 19008523]

Schulz A, Gravlee C, Williams D, Israel B, Mentz G, Rowe Z. Discrimination, symptoms of depression, and self-rated health among African American women in Detriot: Results from a longitudinal analysis. American Journal of Public Health. 2005; 96

Stirratt M, Meyer I, Ouellette S, Gara M. Measuring identity multiplicity and intersectionality: Hierarchical classes analysis (HICLAS) of sexual, racial, and gender identities. Self and Identity. 2008; 7:89-111.

Swim J, Johnson K, Pearson N. Daily experiences with heterosexism: Relations between heterosexist hassles and psychological well-being. Journal of Social and Clinical Psychology. 2009; 28:597629.

Ueno K. Sexual orientation and psychological distress in adolescence: Examining interpersonal stressors and social support processes. Social Psychology Quarterly. 2005; 68:258-277.

Williams D, Mohammed S. Discrimination and racial disparities in health: Evidence and needed research. Journal of Behavioral Medicine. 2009; 32:20-47. [PubMed: 19030981]

Yip T, Gee G, Takeuchi D. Racial discrimination and psychological distress: The impact of ethnic identity and age among immigrant and United States-born Asian adults. Developmental Psychology. 2008; 44 


\section{Table 1a}

Weighted Estimates of Demographic Characteristics by Sexual Identity (Source: NESARC Wave 2, 20042005), Men

\begin{tabular}{|c|c|c|c|c|}
\hline & $\begin{array}{c}\text { Gay } \\
\mathbf{n}=190 \\
\text { Est. } \%(\mathbf{9 5 \%} \text { CI })\end{array}$ & $\begin{array}{c}\text { Bisexual } \\
\mathbf{n}=\mathbf{8 1} \\
\text { Est. } \%(\mathbf{9 5 \%} \text { CI })\end{array}$ & $\begin{array}{c}\text { Heterosexual }^{a} \\
\mathrm{n}=\mathbf{1 4 , 1 0 9} \\
\text { Est.\% }(\mathbf{9 5 \%} \mathrm{CI})\end{array}$ & $\chi^{2}(\mathrm{df})$ \\
\hline \multicolumn{5}{|l|}{ Age } \\
\hline $18-24$ years & $7.3(4.1-12.8)$ & $7.6(3.1-17.2)$ & $8.2(7.6-8.8)$ & \multirow[t]{5}{*}{$52.6(5.7)^{* *}$} \\
\hline $25-44$ & $45.2(37.7-52.9)$ & 29.3(18.6-42.9) & $39.2(38.1-40.3)$ & \\
\hline $45-64$ & $43.9(36.8-51.3)$ & $40.4(28.5-53.6)$ & $35.4(34.4-36.4)$ & \\
\hline 65 and older & $3.6(1.9-6.7)$ & $22.7(14.0-34.6)$ & $17.2(16.3-18.1)$ & \\
\hline Mean Age $(95 \%$ CI) & $43.4(41.3-45.5)$ & $50.7(46.7-54.6)$ & $47.3(46.8-47.7)$ & \\
\hline \multicolumn{5}{|l|}{ Race/Ethnicity } \\
\hline White & $74.6(66.9-81.0)$ & $76.2(61.7-86.4)$ & $74.9(68.0-74.3)$ & \multirow[t]{5}{*}{$13.1(6.5)$} \\
\hline Black & $5.6(3.2-9.7)$ & $13.0(5.5-27.8)$ & $10.1(8.8-11.4)$ & \\
\hline American Indian & $4.5(1.6-11.6)$ & $0.5(0.1-3.5)$ & $2.0(1.7-2.5)$ & \\
\hline Asian Pacific Islander & $3.2(1.0-10.1)$ & $0.9(0.1-6.6)$ & $4.4(3.3-5.7)$ & \\
\hline Hispanic & $12.1(7.8-18.4)$ & $9.4(5.4-15.9)$ & $12.3(10.0-15.0)$ & \\
\hline \multicolumn{5}{|l|}{ Income } \\
\hline$\$ 0-\$ 19,999$ & $28.7(21.3-37.4)$ & $40.1(28.7-52.6)$ & $27.7(26.4-29.0)$ & \multirow[t]{4}{*}{$10.2(5.6)$} \\
\hline$\$ 20,000-\$ 34,999$ & $25.8(18.2-35.2)$ & $29.5(18.5-43.5)$ & $24.5(23.5-25.6)$ & \\
\hline$\$ 35,000-\$ 69,999$ & $27.6(21.4-35.0)$ & $23.9(15.5-35.0)$ & $31.1(30.0-32.2)$ & \\
\hline$\$ 70,000+$ & $17.9(11.8-26.1)$ & $6.6(3.0-13.8)$ & $16.7(15.4-18.1)$ & \\
\hline Any past year (mood or anxiety) mental health disorder $b$ & $25.3(18.7-33.3)$ & 20.1(11.4-32.9) & $13.0(12.2-13.8)$ & $12.6(2.0)^{* *}$ \\
\hline $\begin{array}{l}\text { NOTE: Reported } \mathrm{p} \text {-values are based on design-adjusted Rac } \\
* * \\
\mathrm{p}<.01 \text {, Confidence Intervals based on logit transformatior }\end{array}$ & $\begin{array}{l}\text { cott chi-square tes } \\
\text { echnique (see Hee }\end{array}$ & $\begin{array}{l}\text { statistics } \\
\text { inga et al. 2010). }\end{array}$ & & \\
\hline Heterosexuals included only for purposes of demographic & mparison. & & & \\
\hline
\end{tabular}




\section{Table 1b}

Weighted Estimates of Demographic Characteristics by Sexual Identity (Source: NESARC Wave 2, 20042005), Women

\begin{tabular}{|c|c|c|c|c|}
\hline & 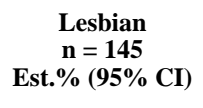 & $\begin{array}{c}\text { Bisexual } \\
\mathrm{n}=161 \\
\text { Est.\% }(\mathbf{9 5 \%} \text { CI })\end{array}$ & $\begin{array}{c}\text { Heterosexual }^{a} \\
\mathrm{n}=19,489 \\
\text { Est. } \%(95 \% \mathrm{CI})\end{array}$ & $\chi^{2}(\mathrm{df})$ \\
\hline \multicolumn{5}{|l|}{ Age } \\
\hline $18-24$ years & $2.0(0.6-6.9)$ & $25.7(17.8-35.5)$ & $7.0(6.4-7.5)$ & $88.7(5.5)^{* *}$ \\
\hline $25-44$ & $61.7(51.7-70.8)$ & $50.2(41.1-59.3)$ & $37.6(36.6-38.5)$ & \\
\hline $45-64$ & $33.0(24.5-42.8)$ & 18.3(12.6-25.9) & $34.0(33.3-34.8)$ & \\
\hline 65 and older & $3.2(1.1-8.8)$ & $5.8(3.0-10.9)$ & $21.6(20.6-22.3)$ & \\
\hline Mean Age $(95 \% \mathrm{CI})$ & $41.9(39.6-44.1)$ & $36.7(34.3-39.2)$ & $49.1(48.7-49.5)$ & \\
\hline \multicolumn{5}{|l|}{ Race/Ethnicity } \\
\hline White & $71.4(60.1-80.5)$ & 68.4(58.6-76.8) & $70.7(67.6-73.7)$ & $3.5(6.0)$ \\
\hline Black & $13.4(8.6-20.1)$ & $13.7(8.4-21.5)$ & $11.9(10.6-13.5)$ & \\
\hline American Indian & $4.5(1.6-12.3)$ & $3.4(1.2-8.9)$ & $2.3(1.9-2.7)$ & \\
\hline Asian Pacific Islander & $4.4(0.9-19.8)$ & $3.1(1.3-7.3)$ & $4.1(3.3-5.2)$ & \\
\hline Hispanic & $6.3(3.3-12.0)$ & $11.5(7.0-18.4)$ & $10.9(8.7-13.5)$ & \\
\hline \multicolumn{5}{|l|}{ Income } \\
\hline$\$ 0-\$ 19,999$ & $23.9(15.6-34.7)$ & $56.8(47.0-66.1)$ & $55.4(54.1-56.7)$ & $43.4(5.5)^{* *}$ \\
\hline$\$ 20,000-\$ 34,999$ & $20.5(13.5-29.8)$ & $22.8(15.6-32.1)$ & $21.8(21.0-22.7)$ & \\
\hline$\$ 35,000-\$ 69,999$ & $38.6(30.0-47.9)$ & $19.0(12.4-28.0)$ & $18.1(17.2-19.0)$ & \\
\hline$\$ 70,000+$ & $17.1(11.1-25.5)$ & $1.3(0.4-3.9)$ & $4.7(4.1-5.3)$ & \\
\hline Any past year (mood or anxiety) mental health disorder $b$ & $35.9(25.9-47.3)$ & $47.4(38.2-56.8)$ & $22.6(21.7-23.5)$ & $23.8(2.0)^{* *}$ \\
\hline
\end{tabular}

NOTE: Reported p-values are based on design-adjusted Rao-Scott chi-square test statistics

** $<$ <.01, Confidence Intervals based on logit transformation technique (see Heeringa et al. 2010).

${ }^{a}$ Heterosexuals included only for purposes of demographic comparison.

${ }^{b}$ Includes any past year major depression, dysthymia, mania, hypomania, panic with and without agoraphobia, social phobia, specific phobia, or generalized anxiety disorder. 


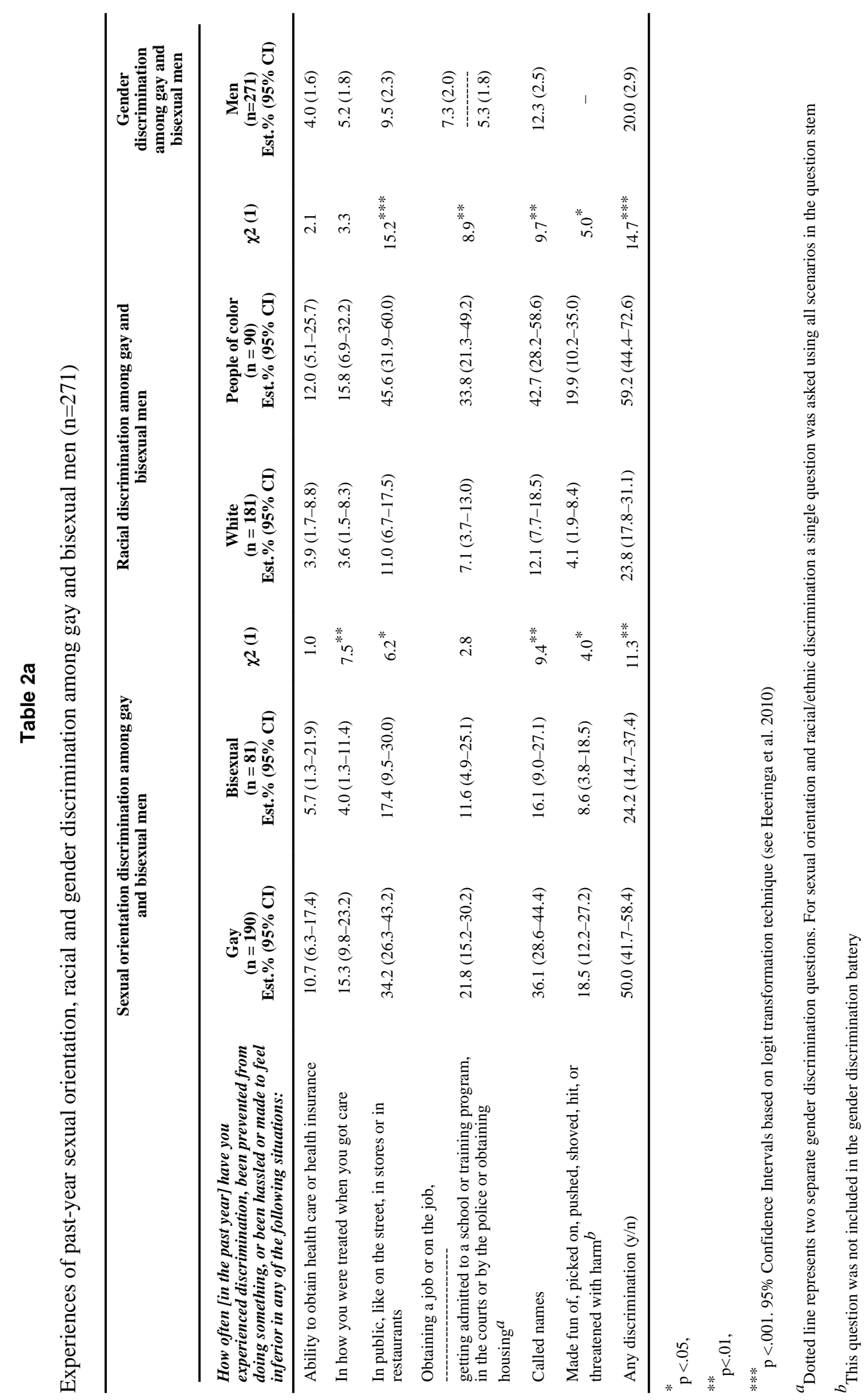




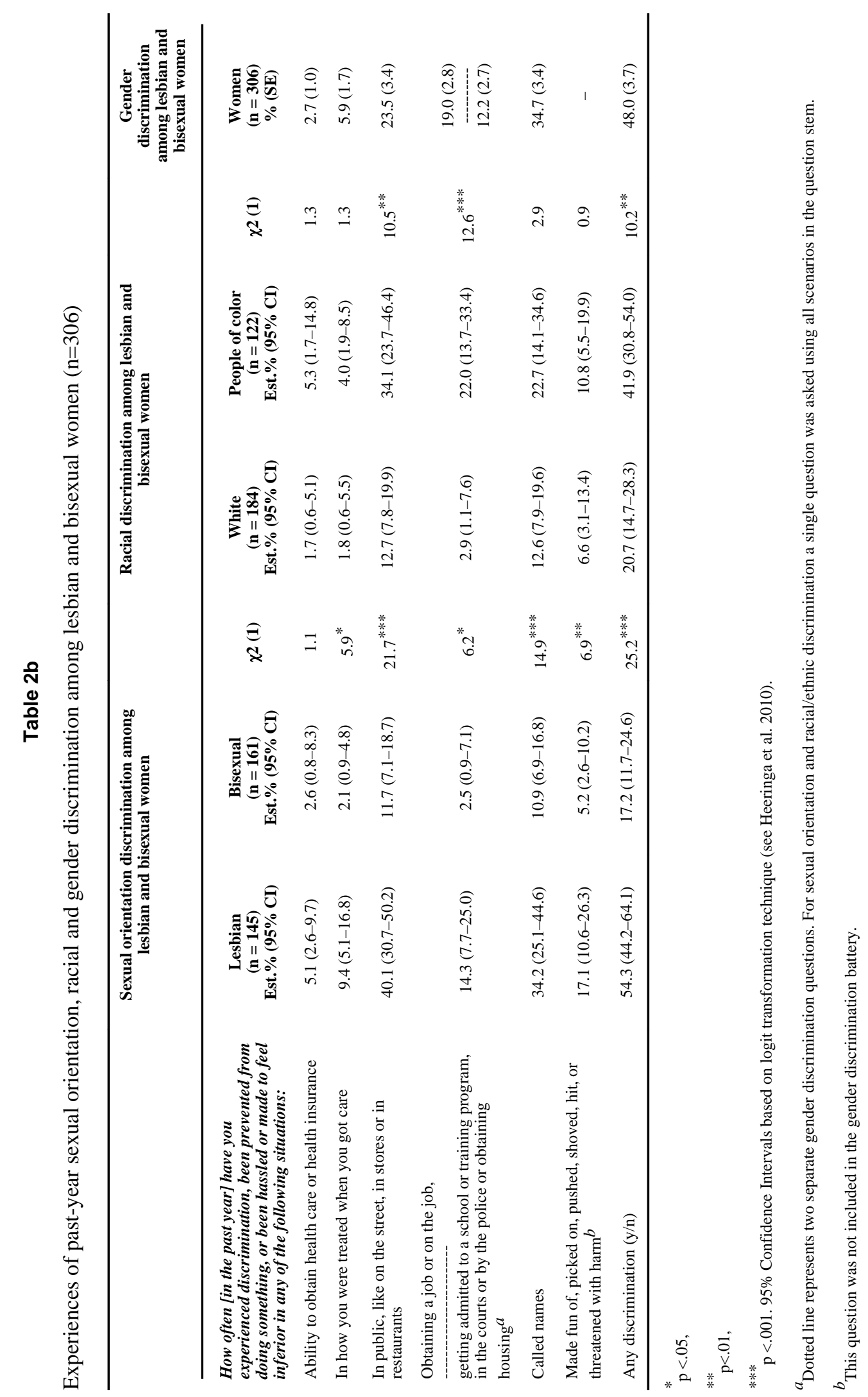




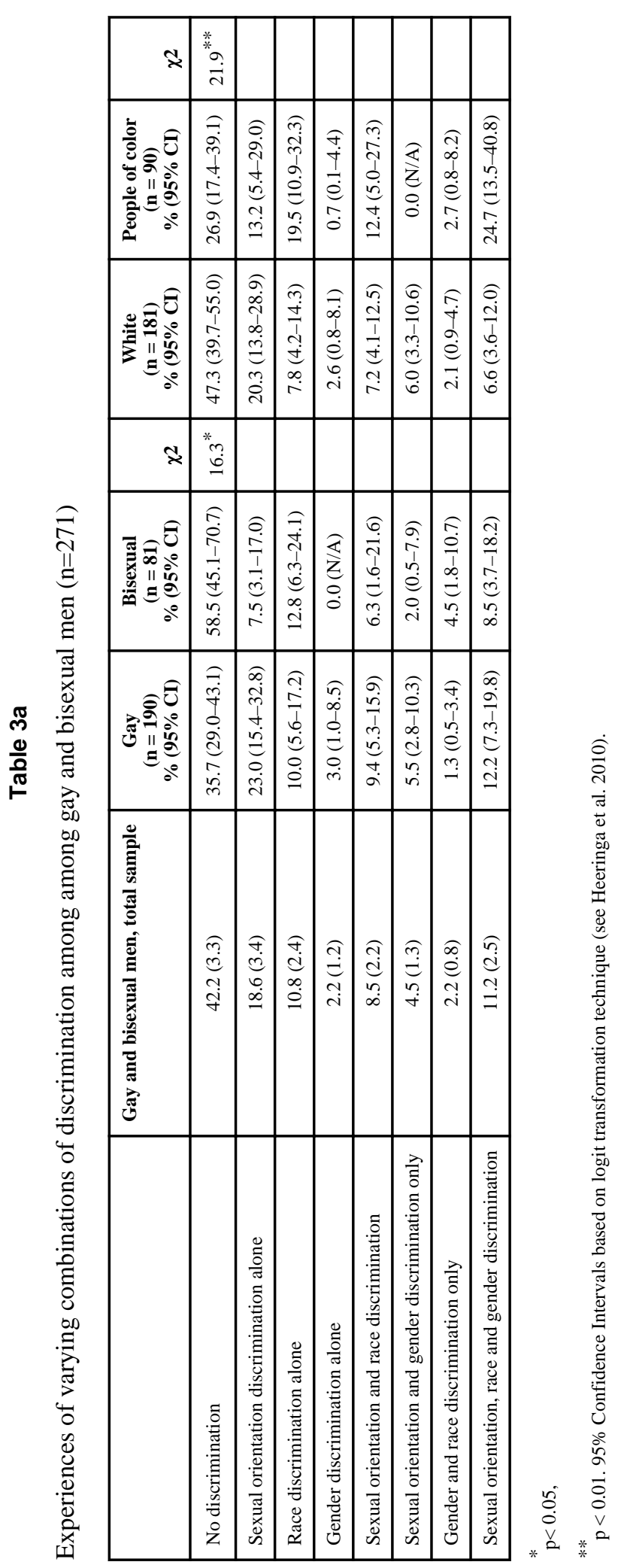

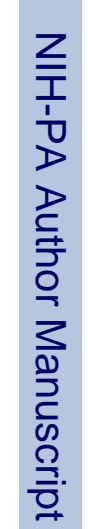

Am J Orthopsychiatry. Author manuscript; available in PMC 2015 January 01. 


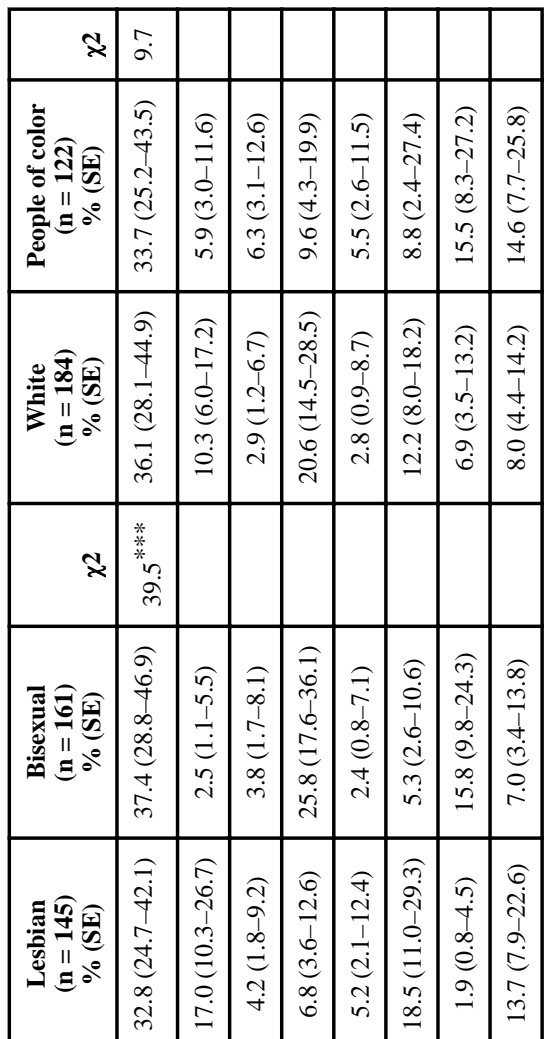


Table 4

Weighted estimates of adjusted odds-ratios for any past year mental health disorder by single, dual or triple types of discrimination $(\mathrm{n}=577)$

\begin{tabular}{|c|c|}
\hline & $\begin{array}{c}\text { Any past year mental health disorder } a \\
\text { Adjusted OR } \\
\text { (95\% CI) }\end{array}$ \\
\hline No discrimination (referent) & - \\
\hline Single type of discrimination $b$ & $1.67(0.97,2.86)$ \\
\hline Dual discrimination ${ }^{c}$ & $2.49(1.47,4.22)$ \\
\hline Triple discrimination $d$ & $3.24(1.51,6.96)$ \\
\hline Bisexual (vs. Gay/Lesbian) & $1.12(0.68,1.84)$ \\
\hline Male (vs. Female) & $0.51(0.31,0.84)$ \\
\hline Other Race (vs. White) & $0.69(0.45,1.07)$ \\
\hline Age & $0.98(0.97,1.00)$ \\
\hline \multicolumn{2}{|l|}{ Income (vs. $<\$ 20,000)$} \\
\hline$\$ 20,000-\$ 34,999$ & $0.50(0.28,0.88)$ \\
\hline$\$ 35,000-\$ 69,999$ & $0.49(0.27,0.89)$ \\
\hline$\$ 70,000+$ & $0.46(0.20,1.07)$ \\
\hline
\end{tabular}

\footnotetext{
${ }^{a}$ Includes any past year major depression, dysthymia, mania, hypomania, panic with and without agoraphobia, social phobia, specific phobia, or generalized anxiety disorder.

${ }^{b}$ Includes sexual orientation discrimination only, race discrimination only, gender discrimination only

${ }^{c}$ Includes sexual orientation and race discrimination, sexual orientation and gender discrimination, and gender and race discrimination

$d_{\text {Includes all three types of discrimination: sexual orientation discrimination, gender discrimination, and race discrimination }}$
} 


\section{Table 5}

Weighted estimates of adjusted odds-ratios for any past year mental health disorder by past year discrimination type among LGB respondents $(n=577)$

\begin{tabular}{|c|c|}
\hline & $\begin{array}{c}\text { Any past year mental health disorder } a \\
\text { Adjusted OR } \\
\text { (95\% CI) }\end{array}$ \\
\hline No discrimination (referent) & - \\
\hline Sexual orientation discrimination alone & $1.19(0.59,2.44)$ \\
\hline Race discrimination alone & $1.67(0.58,4.84)$ \\
\hline Gender discrimination alone & $2.28(1.09,4.78)$ \\
\hline Sexual orientation and race discrimination & $2.25(1.02,4.95)$ \\
\hline Sexual orientation and gender discrimination & $1.76(0.80,3.89)$ \\
\hline Gender and race discrimination & $4.30(1.91,9.68)$ \\
\hline All three types of discrimination & $3.13(1.45,6.74)$ \\
\hline Bisexual (vs. Gay/Lesbian) & $0.93(0.57,1.52)$ \\
\hline Male (vs. Female) & $0.53(0.32,0.88)$ \\
\hline Other Race (vs. White) & $0.67(0.43,1.04)$ \\
\hline Age & $0.98(0.97,1.00)$ \\
\hline \multicolumn{2}{|l|}{ Income (vs. $<\$ 20,000)$} \\
\hline$\$ 20,000-\$ 34,999$ & $0.49(0.28,0.88)$ \\
\hline$\$ 35,000-\$ 69,999$ & $0.48(0.26,0.88)$ \\
\hline$\$ 70,000+$ & $0.46(0.20,1.06)$ \\
\hline
\end{tabular}

${ }^{a}$ Includes any past year major depression, dysthymia, mania, hypomania, panic with and without agoraphobia, social phobia, specific phobia, or generalized anxiety disorder. 